Biofuel Research Journal 19 (2018) 854-862
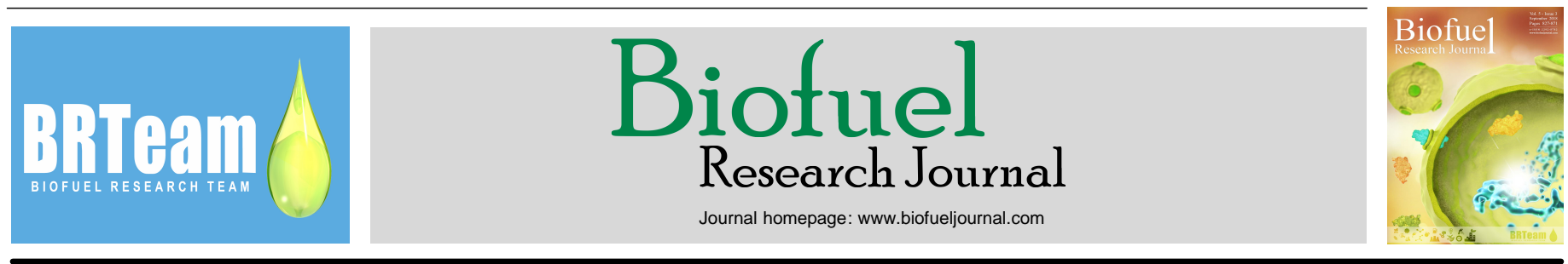

Original Research Paper

\title{
Comparative investigation of the effect of hemispherical and toroidal piston bowl geometries on diesel engine combustion characteristics
}

\author{
M. Channappagoudra ${ }^{1, *}$, K. Ramesh ${ }^{1}$, G. Manavendra ${ }^{2}$ \\ ${ }^{I}$ Department of Mechanical Engineering, U.B.D.T College of Engineering, Davangere, Karnataka, India. \\ ${ }^{2}$ Department of Mechanical Engineering, B.I.E.T, Davangere, Karnataka, India.
}

\section{HIGHLIGHTS}

Combustion characteristics of dairy scum oil biodiesel were investigated.

$>$ Optimized operating conditions for $20 \%$ blend of dairy scum oil biodiesel (B20) were IOP: 230 bar, IT 26.deg.bTDC, CR: 18 , and NH: 5 holes.

$>$ Using dairy scum oil biodiesel, hemispherical and toroidal geometries of diesel engine piston bowl of were compared.

$>$ Engine modification, i.e., TPBG, increased brake thermal efficiency and heat release rate by $5.5 \%$ and $17.24 \%$, respectively.

$>$ TPBG decreased brake specific fuel consumption, HC emission, and CO emission by $8.75 \%, 15 \%$, and $14.47 \%$, respectively.

\section{GRAPHICAL ABSTRACT}

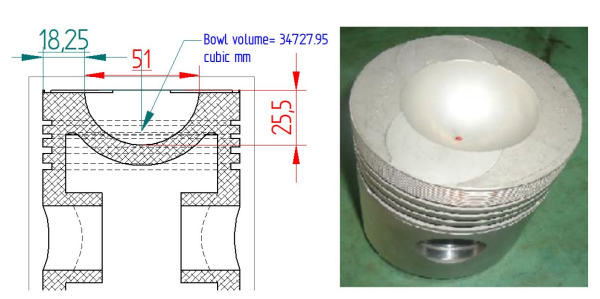

Hemispherical Piston Bowl Geometry (HPBG)

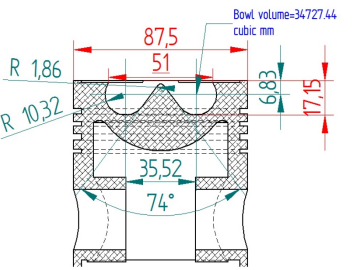

Toroidal Piston Bowl Geometry (TPBG)

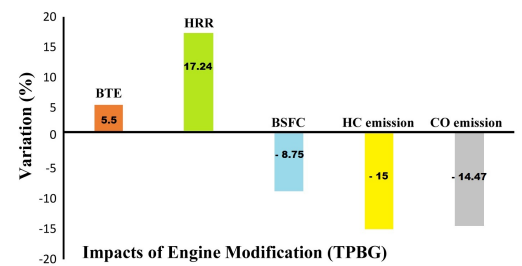

\section{ARTICLE INFO}

\section{Article history:}

Received 25 May 2018

Received in revised form 6 July 2018

Accepted 11 July 2018

Available online 1 September 2018

\section{Keywords:}

Diesel engine

Piston bowl geometry

Nozzle hole

Dairy scum oil biodiesel

Combustion characteristics

\begin{abstract}
Diesel engine parameters are in general more compatible with operating on neat diesel than biodiesel and its blends. Therefore, optimizing operating conditions as well as piston bowl geometry to achieve a better performance with biodiesel in conventional diesel engines is highly essential. In the present study, hemispherical piston bowl geometry (HPBG) of existing diesel engine was modified into toroidal piston bowl geometry (TPBG) to evaluate the performance of a diesel engine running on a $20 \%$ blend of dairy scum oil biodiesel (B20). The experimental results revealed increased brake thermal efficiency and heat release rate by $5.5 \%$ and $17.24 \%$, respectively, while brake specific fuel consumption, $\mathrm{HC}$ emission, and CO emission were decreased by $8.75 \%, 15 \%$, and $14.47 \%$, respectively, in response to the engine modification applied. Such improvements using the TPBG could be attributed to improved fuel atomization, reduction of fuel droplet size, increased cylinder temperature, enhanced squishswirl, and turbulence kinetic energy during combustion. The findings of the present study could pave the way for the fabrication of diesel engines, which are more efficiently compatible with biodiesel and its blends.
\end{abstract}

* Corresponding author at: Tel.: +91 8050900743

E-mail address: manjunath6729@gmail.com

Please cite this article as: Channappagoudra M., Ramesh K., Manavendra G. Comparative examination of effect of hemispherical and toroidal piston bowl geometries on diesel engine performance. Biofuel Research Journal 19 (2018) 854-862. DOI: 10.18331/BRJ2018.5.3.5 


\begin{tabular}{|ll|}
\hline Abbreviations & \\
BSFC & Brake Specific Fuel Consumption \\
BTE & Brake Thermal Efficiency \\
BP & Brake Power \\
bTDC & Before Top Dead Centre \\
CC & Combustion Chamber \\
CFD & Computational Fluid Dynamics \\
CR & Compression Ratio \\
deg. & Degrees \\
Diesel-SE & Diesel-operated Standard Engine \\
DSOME & Dairy Scum Oil Methyl Ester (biodiesel) \\
DSOME-B20 & 20\% Biodiesel+80\% Diesel (B20) \\
DSOME-B20-SE & 20\% Biodiesel-operated Standard Engine \\
EGR & Exhaust Gas Recirculation \\
HPBG & Hemispherical Piston Bowl Geometry \\
HPBG-ME & Modified Engine with HPBG Piston Geometry \\
HRR & Heat Release Rate \\
IDP & Ignition Delay Period \\
IOP & Injector Opening Pressure \\
IT & Injection Timing \\
ME & Modified Engine \\
NH & Nozzle Hole \\
SE & Standard Engine \\
TDC & Top Dead Centre \\
TKE & Turbulent Kinetic Energy \\
TPBG & Toroidal Piston Bowl Geometry \\
TPBG-ME & Modified Engine with TPBG Piston Geometry \\
TRCC & Toroidal Combustion Chamber \\
& \\
\hline
\end{tabular}

\section{Introduction}

As the industrialization process is growing on a daily basis so is looking into more substitute fuels to replace petroleum-oriented products; alternative fuels locally available and with lesser emissions (Ramadhas et al., 2004). In line with that, biodiesel produced from non-edible oil feedstocks through transesterification is considered as an ideal substitute for the mineral diesel fuel (Agarwala et al., 2008). Biodiesel is renewable, sustainable, and possesses similar properties to those of petroleum diesel (Selaimia et al., 2015). In spite of its favorable attributes, biodiesel owing to its oxygen content, leads to higher NOx emissions proportional to its inclusion rate in fuel blends (Geng et al., 2017). It is in general believed that the utilization of biodiesel would not affect the weight loss and surface of the fuel injector equipment (FIE) and hence, lesser wear would be expected when compared with mineral diesel (Reddy et al., 2016).

Slight modifications in diesel engine parameters like injector operating pressure (IOP), injection timing (IT), nozzle geometry, and compression ratio (CR) could contribute to improved performance in diesel engines fueled with biodiesel. For instance, the higher viscosity and density of biodiesel necessitate higher IOPs to ensure proper fuel atomization followed by improved fuel-air mixing with smaller fuel droplets and more complete combustion (Badami et al., 1999; Hountalas et al., 2003; Belagur and Chitimini, 2010; Venkanna and Reddy, 2011; Behera and Murugan, 2013). In addition, advanced IT when using biodiesel could enhance engine performance leading to lower HC and $\mathrm{CO}$ emissions while could also compensate for the higher NOx emission of biodiesel in comparison with mineral diesel (Mani and Nagarajan, 2009; Hwang et al., 2014; Senthil et al., 2015). Diesel engines operating on biodiesel could show improved combustion behaviors in response to higher CRs as higher CRs would contribute to higher cylinder temperatures and pressures leading to more complete combustion (Mohanraj and Mohan Kumar, 2013; Jose et al., 2014; Miraculas et al., 2016; Yadav et al., 2017). As proven by both experimental and simulation results, the design of nozzle hole (NH) is also a truly critical parameter to achieve improved spray characteristics and consequently improved emissions profile and performance in the combustion chamber (Agarwal et al., 2015).

As mentioned earlier, biodiesel inclusion in diesel is associated with increased NOx emissions. Nozzle geometry modification (modifying injector $\mathrm{NH}$ from 5 (base) to 6 holes) was reportedly found to be a feasible solution to reduce NOx emission of biodiesel-operated diesel engines (Lahane and
Subramanian, 2014). The presence of cavitation and turbulence in nozzles has a noteworthy influence on improving spray behaviors (He et al., 2013). At an injection pressure of 250 bar, brake thermal efficiency (BTE) and brake specific fuel consumption (BSFC) were improved and emissions were decreased with modified nozzle ( 5 hole) when compared to baseline nozzle (3 hole) of a standard engine (SE) (Vairamuthu 1 et al., 2015). In a different study, it was shown that an 8 hole nozzle led to increased BSFC and engine torque a result of higher fuel injection velocity and improved fuel-air mixing while also resulted in reduced $\mathrm{NOx}$ and $\mathrm{CO}$ emissions when compared to 6, 7, and 9 hole nozzles (Jafari and Ganji, 2013). It has also been revealed that fuel injector nozzles with smaller orifice diameters would exhibit considerably improved engine performance and emission characteristics (Kumar et al., 2018).

Along with injection strategies and/or changing the other parameters, piston bowl shape could also strongly influence engine performance (De Risi et al., 2003). From the computational fluid dynamics (CFD) simulations, it has been observed that symmetric toroidal vortices of reentrant piston bowl shape would enhance the squish-swirl and turbulence kinetic energy (TKE) during compression stroke when compared to openpiston bowl shape. Hence swirl, squish, and turbulence is strongly influenced by the piston bowl geometry in diesel engines (Payri et al., 2004; Song et al., 2008; Prasad et al., 2011). For instance, combustion chambers with bottom corners have been reported to result in improved thermal efficiency and reduced NOx, CO, and soot emissions when compared to lip shaped combustion chambers (Ghodke and Suryawanshi, 2015). Diesel engine operation with $20 \%$ Jatropha methyl esters led enhanced performance and reduced $\mathrm{HC}, \mathrm{CO}$, and smoke emissions with toroidal reentrant combustion chamber (TRCC) in comparison with spherical and toroidal combustion chamber (Mamilla et al., 2013). The TRCC geometries has been shown to be associated with improved BTE, peak pressure, and heat release rate (HRR) as well as reduced $\mathrm{BSFC}$, ignition delay period (IDP), CO, HC, and smoke emissions; all attributing to higher air motion, squish, and fuel-air mixing rates when compared to hemispherical combustion chamber (HCC) geometries (Jaichandar and Annamalai, 2012).

The substandard performance of biodiesel-operated diesel engine could be enhanced by providing squish, turbulence, rapid, and proper fuel-air mixing in the cylinder using robust designs in piston bowl geometry along with the implementation of optimized engine parameters depending on the properties of the biodiesel produced from a given oil feedstock. It has been reported in the published literature that higher IOPs (Badami et al., 1999; Hountalas et al., 2003; Belagur and Chitimini, 2010; Venkanna and Reddy, 2011; Behera and Murugan, 2013), advanced ITs (Mani and Nagarajan, 2009; Hwang et al., 2014; Senthil et al., 2015), CRs (Mohanraj and Mohan Kumar, 2013; Jose et al., 2014; Miraculas et al., 2016; Yadav et al., 2017), and higher NH numbers (Vairamuthul et al., 2015) would improve diesel engine combustion characteristics.

Accordingly, the present study was set to first find the optimal engine parameters (i.e., IOP, IT, CR, and $\mathrm{NH}$ ) when operating on the investigated biodiesel (B20). Subsequently, the effect of piston bowl geometry modification on the emission and performance characteristics of the diesel engine under optimal engine parameters were assessed. A waste-oriented oil feedstock, i.e., dairy scum oil was used for biodiesel production in order to enhance the sustainability aspects of the alternative fuel used.

\section{Materials and Methods}

\subsection{Biodiesel preparation and properties}

Biodiesel preparation process from dairy scum oil is demonstrated in Figure 1. Briefly, the white and semisolid dairy scum was heated at 50-60 ${ }^{\circ} \mathrm{C}$ to convert it into liquid followed by filtration prior to its introduction in the transesterification reactor. In the reactor, the scum oil was transesterified with methanol in the presence of $\mathrm{KOH}$ as catalyst. Upon the completion of the reaction, glycerin was removed and crude biodiesel was washed with plain water three times to remove the impurities, i.e., acids, soaps, and residual catalyst. Finally, the purified product was dried at 110 ${ }^{\circ} \mathrm{C}$.

The main properties of dairy scum oil methyl esters (DSOME) and its blends such as viscosity, calorific value, density, flash point, and fire point were determined as per ASTM-6751 standards (Table 1). The density of 


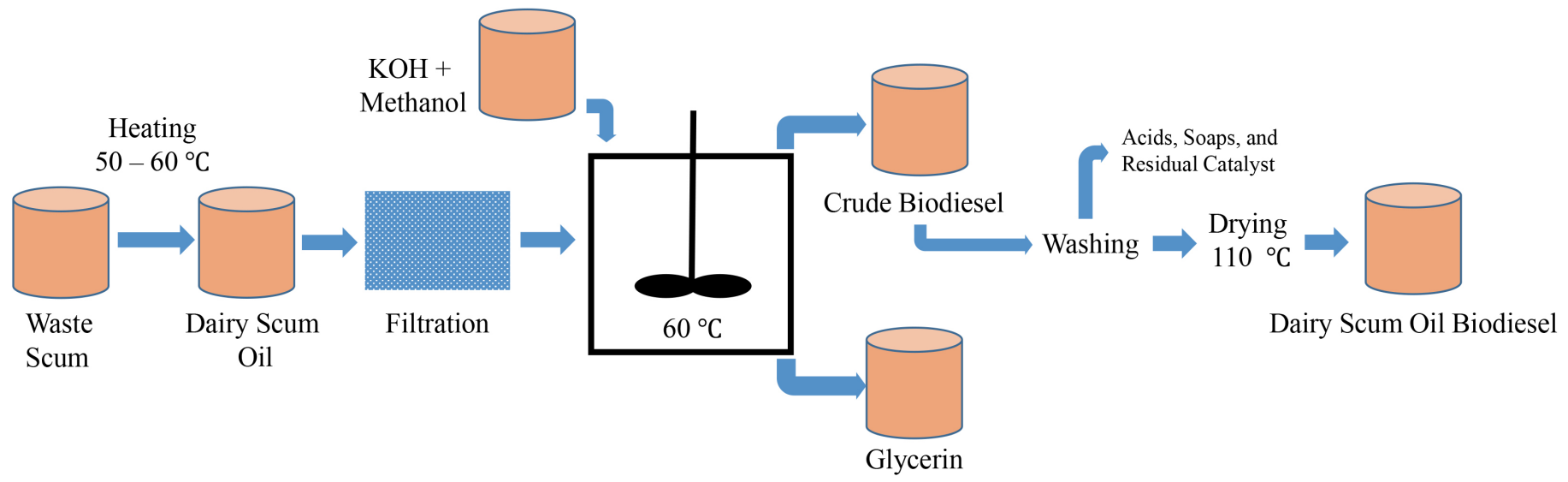

Fig.1. Schematic presentation of the biodiesel preparation process from dairy scum oil.

Table 1.

Properties of the fuel samples investigated.

\begin{tabular}{lcccc}
\hline Properties & Methods (IS 1448) & Diesel & B20 & B100 \\
\hline Density $\left(\mathbf{k g} / \mathbf{m}^{3}\right)$ & P:16 & 830 & 840 & 870 \\
Viscosity at $\mathbf{4 0}{ }^{\circ} \mathbf{C}(\mathbf{c S t})$ & P:25 & 2.9 & 2.98 & 4.36 \\
Calorific value $(\mathbf{k J} / \mathbf{k g})$ & P:6 & 43000 & 40890 & 38012 \\
Flash Point $\left({ }^{\circ} \mathbf{C}\right)$ & P:69 & 50 & 58 & 130 \\
Fire point $\left({ }^{\circ} \mathbf{C}\right)$ & P:69 & 60 & 68 & 142 \\
\hline
\end{tabular}

biodiesel blends was measured using a hydrometer at $30^{\circ} \mathrm{C}$. The flash and fire points of the fuels were computed by using a Pensky-Martens apparatus at the $40-250{ }^{\circ} \mathrm{C}$ temperature range. A Bomb calorimeter was used to calculate the heating value of the various fuel blends. A Redwood viscometer was used to calculate the kinematic viscosity of biodiesel at a $40{ }^{\circ} \mathrm{C}$.

\subsection{Experimental setup}

A Kirloskar, $3.5 \mathrm{~kW}$ (TV1) diesel engine (Fig. 2) was used to conduct the combustion experiments. The specifications of the SE used are given in Table 2. Instruments used for the defined work included diesel engine-test rig, ECU, exhaust gas analyzer, burette and stopwatch, digital manometer, Chromel Alumel (K-Type) thermocouples. "Engine soft LV" software was employed for online combustion analysis. The combustion pressure at various crank angles was determined by using Piezo sensor and crank angle sensor. The test engine was operated at the constant speed of $1500 \mathrm{rpm}$ and it was coupled with a dynamometer for loading the engine. Water circulation was used to prevent overheating. Temperature sensors were used to measure water jacket temperature as well as calorimeter water temperatures. The fuel and air flow rates were determined using flow sensors. Baseline engine readings were performed using neat diesel and an average of three readings was considered for the examination. Airrex Automotive Emission Analyzer HG-540 was used to measure the exhaust emissions, i.e., $\mathrm{HC}, \mathrm{CO}$, and $\mathrm{NOx}$.

\subsection{Engine modifications}

The influence of piston bowl geometry when using $20 \%$ blend of DSME

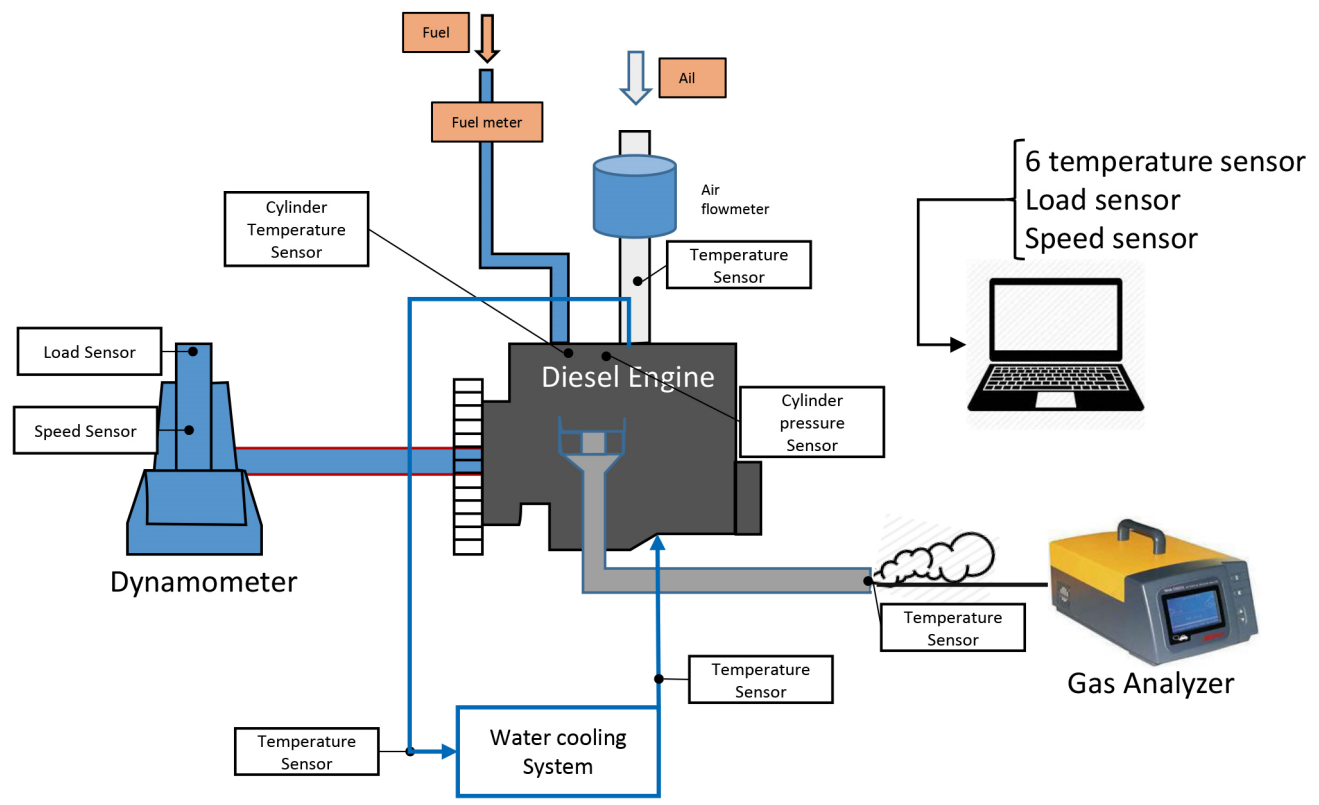

Fig.2. Schematic presentation of the engine set-up used.

Please cite this article as: Channappagoudra M., Ramesh K., Manavendra G. Comparative examination of effect of hemispherical and toroidal piston bowl geometries on diesel engine performance. Biofuel Research Journal 19 (2018) 854-862. DOI: 10.18331/BRJ2018.5.3.5 
Table 2.

TV1engine specifications.

\begin{tabular}{ll}
\hline Parameters & Specifications \\
\hline Engine suppliers & Apex Innovations Pvt. Ltd \\
Type & TV1 (Kirloskar) \\
Cubic capacity & $661 \mathrm{cc}$ \\
Bore and stroke length & $87.5 \mathrm{~mm} \mathrm{X} 110 \mathrm{~mm}$ \\
Injector opening pressure & $210 \mathrm{bar}$ \\
No. of Nozzle holes & 3 holes of $0.280 \mathrm{~mm}$ diameter \\
Piston bowl geometry & Hemispherical \\
Rated power & $3.5 \mathrm{~kW}$ \\
Injection timing & $23^{\circ} \mathrm{bTDC}$ (diesel) \\
No. of cylinder/stroke & One/Four \\
Compression ratio & 17.5 \\
Dynamometer & Eddy current \\
Software used & Engine soft \\
\hline
\end{tabular}

(B20) in a modified diesel engine (IOP:230 bar, IT:26.deg.bTDC, CR:18, NH:5 holes) was explored and the experimental results obtained were compared with those of a standard diesel engine (IOP:210 bar, IT:26.deg.bTDC, CR:17.5, $\mathrm{NH}: 3$ holes). The schematic and photographic views as well as the specifications of the different nozzles used are given in Figures 3 and 4, and Table 3, respectively.

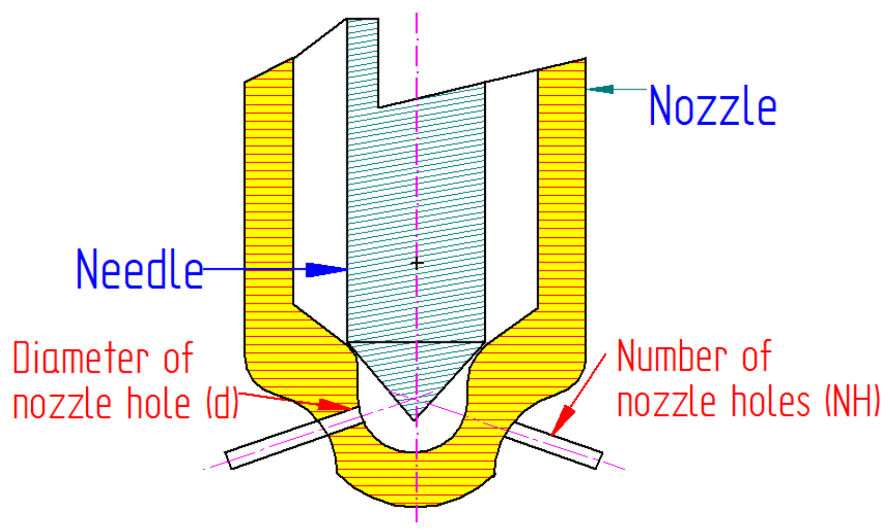

Fig.3. Schematic view of the fuel injector nozzle.
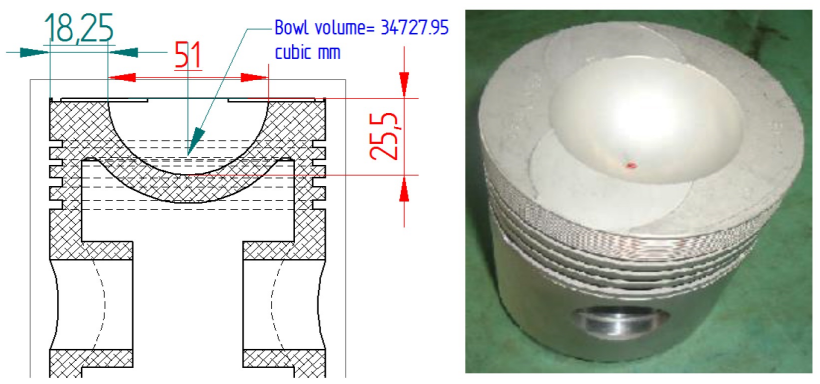

(a) HPBG

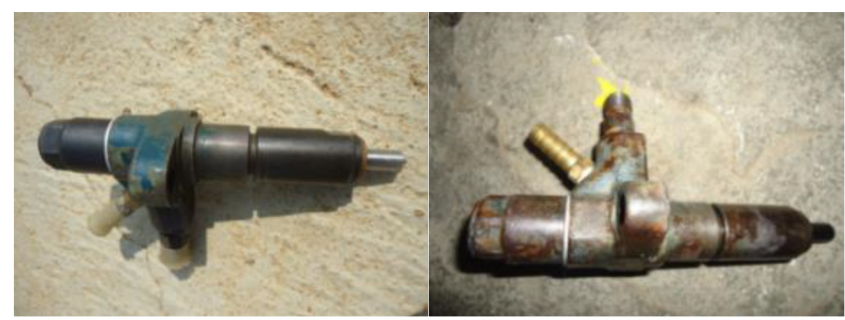

Fig.4. Photographic view of 3- and 5-hole nozzle fuel injectors.

An efficient air-fuel mixing (swirl and squish) inside the cylinder of direct injection diesel engines mainly depends on the piston bowl geometry. In this study, the SE hemispherical piston bowl geometry (HPBG) which is centrally positioned was modified into a toriodal piston bowl geometry (TPBG) without altering the bowl diameter (HPBG: $51 \mathrm{~mm}$ and TPBG: 51 $\mathrm{mm}$ ) and bowl volume. Hence, bowl volume was identical for both pistons (HPBG bowl volume: $34727.95 \mathrm{~mm}^{3}$ and TPBG bowl volume: 34727.44 $\mathrm{mm}^{3}$ ). The concept behind this toroidal geometry was to more completely utilize oxygen by providing a powerful squish. Cross-sectional schematic presentation including dimensions and photographic view of the piston bowl shapes as well as their specifications are represented in Figure 5 and Table 3, respectively. The tests were conducted on a diesel engine at various loads $(20,40,60,80$, and $100 \%)$ to investigate the performance and emission behaviors of the diesel engine operated on 20\% DSME. At the very beginning, the SE was operated on neat diesel to get the baseline readings. Subsequently, the main experiments were carried out and an average of three readings were considered for assessment the investigated parameters. The photographic views of the piston disassembled after use are shown in Figure 6.

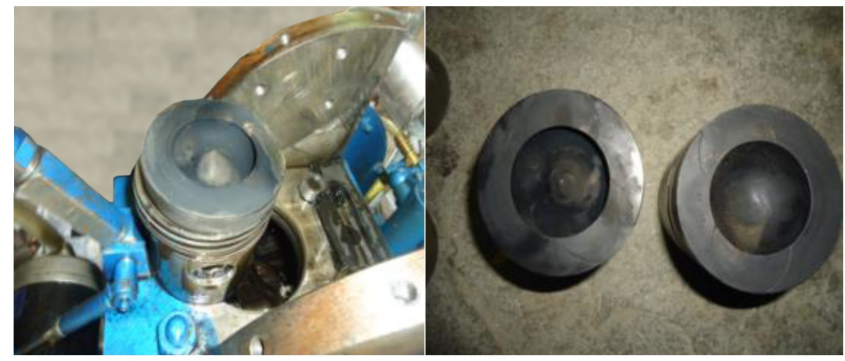

Fig.6. Photographic presentations of the piston disassembled after use.
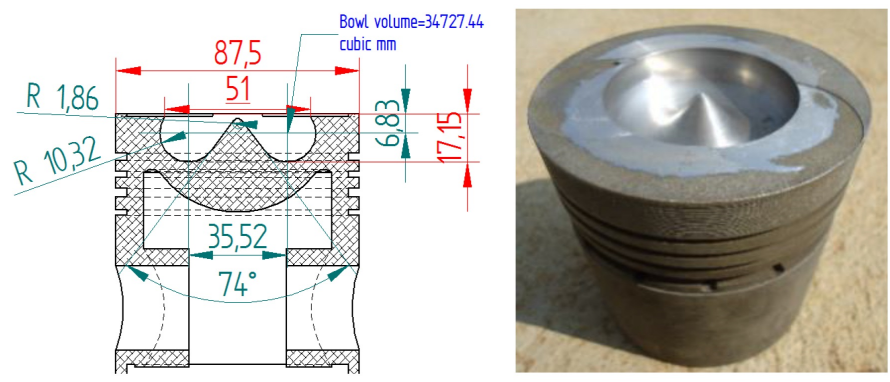

(b) TPBG

Note: all dimensions are in $\mathrm{mm}$

Fig.5. Schematic and photographic views of the different piston bowl shapes used. 
Table 3.

Specifications of the employed pistons and fuel injectors

\begin{tabular}{lllllll}
\hline Sl. No & \multicolumn{3}{c}{ Piston } & & \multicolumn{2}{c}{ Nozzle } \\
\cline { 2 - 6 } & Particulars & Standard & Modified & Particulars & Standard & Modified \\
\hline 1 & Name & HPBG & TPBG & Number of hole & 3 & 5 \\
2 & Bowl Volume $\left(\mathrm{mm}^{3}\right)$ & 34727.95 & 34727.44 & Part name & DLL110S639 & DLLA142S1033 \\
3 & Throat diameter $(\mathrm{mm})$ & 51 & 51 & Hole diameter $(\mathrm{mm})$ & 0.280 & 0.240 \\
4 & Bowl depth $(\mathrm{mm})$ & 25.5 & 17.15 & Area $\left(\mathrm{mm}^{2}\right)$ & 0.0616 & 0.0452 \\
5 & Piston diameter $(\mathrm{mm})$ & 87.5 & 87.5 & Spray angle $\left(\theta^{\circ}\right)$ & 110 & 142 \\
\hline
\end{tabular}

\section{Results and Discussion}

\subsection{Effect of various engine parameters on diesel engine performance}

Figure 7 shows variations in BTE against brake power (BP) for different IOPs. The higher BTE of diesel in comparison with B20 could be explained by its higher heating value and lower viscosity. As presented, there was a positive correlation between IOP and BTE caused by improved atomization, vaporization, and better air-fuel mixing in response to increasing IOP. At an IOP of 230 bar, enhanced air-fuel mixing was observed at higher loads leading to maximum BTE, it was still less than that of diesel though. On the contrary, by increasing IOP more than 240 bar, BTE was reduced. This might be due to unfavorable decreases in fuel droplets size (very fine particles) leading to too low relative velocity and consequently, sluggish combustion (Belagur and Chitimini, 2010; Venkanna and Reddy, 2011; Behera and Murugan, 2013). Based on the BTE results obtained IOP of 230 bar was found as the optimal value for B20 operation.

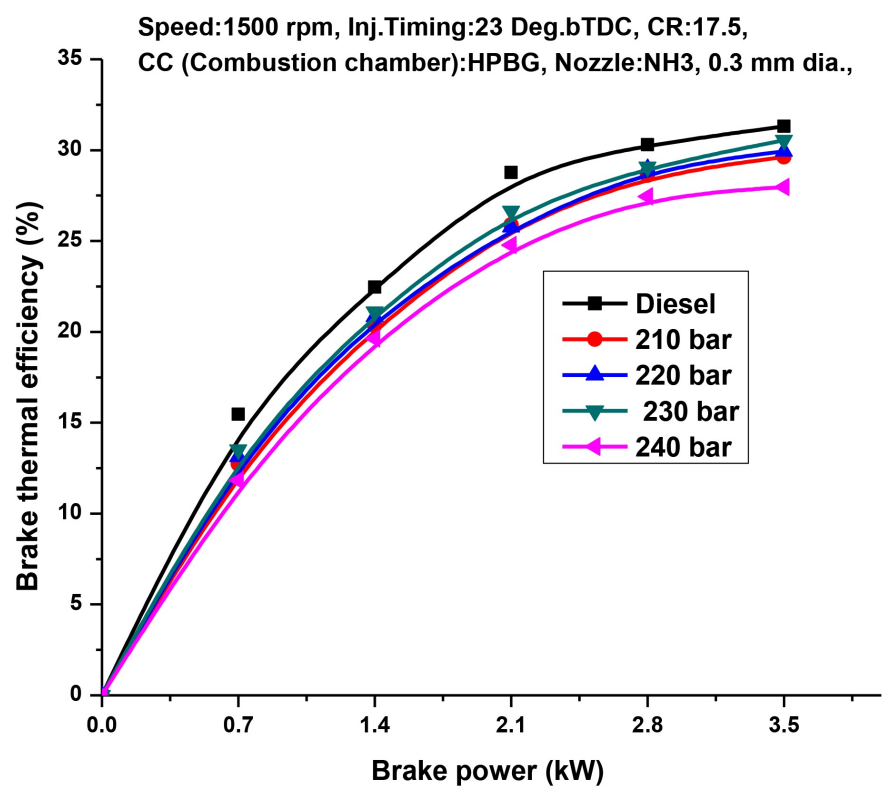

Fig.7. Brake thermal efficiency $v s$. brake power for neat diesel and DSOME-B20 at different injector opening pressures (IOP)

The variations in BTE against BP for different ITs are represented in Figure 8. As presented, by advancing the fuel IT (from 23.deg.bTDC to 26.deg.bTDC), BTE was increased. This might be attributed to more time availability for airfuel mixing in the cylinder resulting in an improved combustion process and consequently, releasing more heat in the cylinder (Mani and Nagarajan, 2009; Senthil et al., 2015). Whereas by retarding the IT from 23.deg.bTDC to 20.deg.bTDC, BTE was reduced. The experimental BTE values for Diesel (23.deg.bTDC) and B20 at full load at different ITs, i.e., 20.deg.bTDC,
23.deg.bTDC, 26.deg.bTDC, and 29.deg.bTDC were $31.32 \%, 28.21 \%$, $30.55 \%, 31.03 \%$, and $29.15 \%$, respectively. Therefore, for DSOME-B20 26.deg.bTDC was considered as the optimum IT leading to the highest BTE value of $31.03 \%$ or in better words, the closest BTE value to that of neat Diesel (i.e., $31.32 \%$ ).

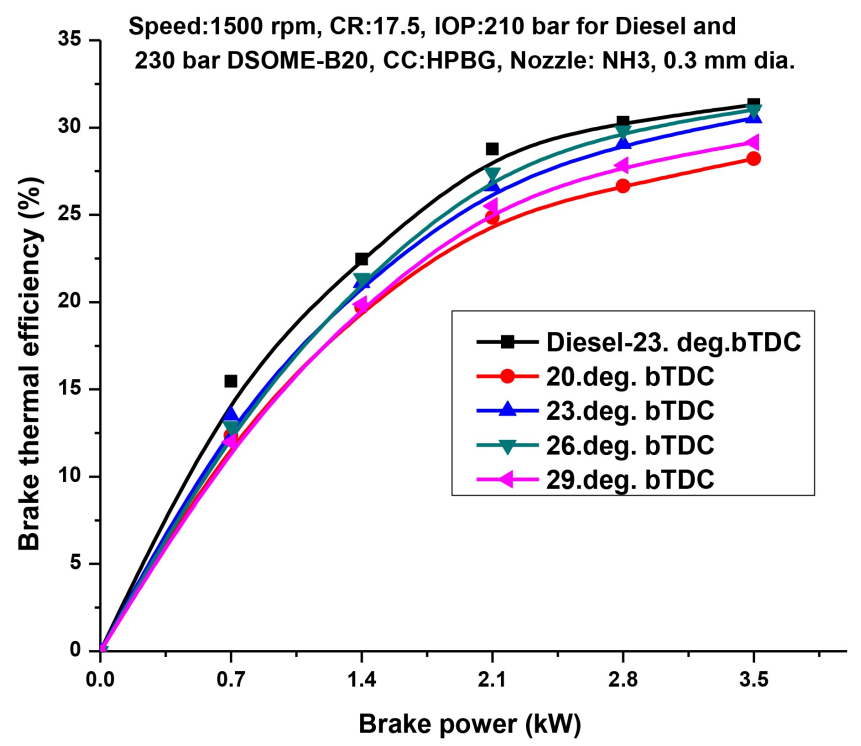

Fig.8. Brake thermal efficiency $v s$. brake power for neat diesel and DSOME-B20 at differen injection timings (IT)

Figure 9 depicts the variations in BTE against BP for different CRs. As the CR was increased, BTE was also increased. This may be attributed to higher air temperature and to better mixing of fuel and air in the cylinder resulting in faster evaporation of the fuel particles and consequently more complete combustion (Mohanraj and Mohan Kumar, 2013; Miraculas et al. 2016). At full load when the CR was increased from CR 16 to 18, BTE was increased from $30.03 \%$ to $31.15 \%$, respectively. The BTE obtained at the highest CR (i.e., 18) when running on DSOME-B20 was comparable to that of neat diesel (i.e., $31.32 \%$ ). Therefore, the $\mathrm{CR}$ of 18 could be regarded as the most optimal CR for DSOME-B20 operation. Lower CRs resulted in lower BTE values which could be ascribed to the dilution of residual gas and consequent slower combustion process.

Figure 10 represents the variations in BTE against BP for different nozzles. The SE operation with diesel (diesel-baseline) showed a higher BTE value of $31.32 \%$ when compared with the 3- and 4-hole nozzles using B20 fuel blend at full load. However, 5-hole nozzle resulted in a higher BTE value of $31.5 \%$ probably owing to better atomization and fuel-air mixing inside the combustion chamber, which consequently led to rapid evaporation and more complete combustion. The lowest BTE value was recorded for the 4-hole nozzle which could be explained by its smaller 
Speed:1500 rpm, Inj.Timing:26.deg.bTDC, IOP:210 bar for Diesel

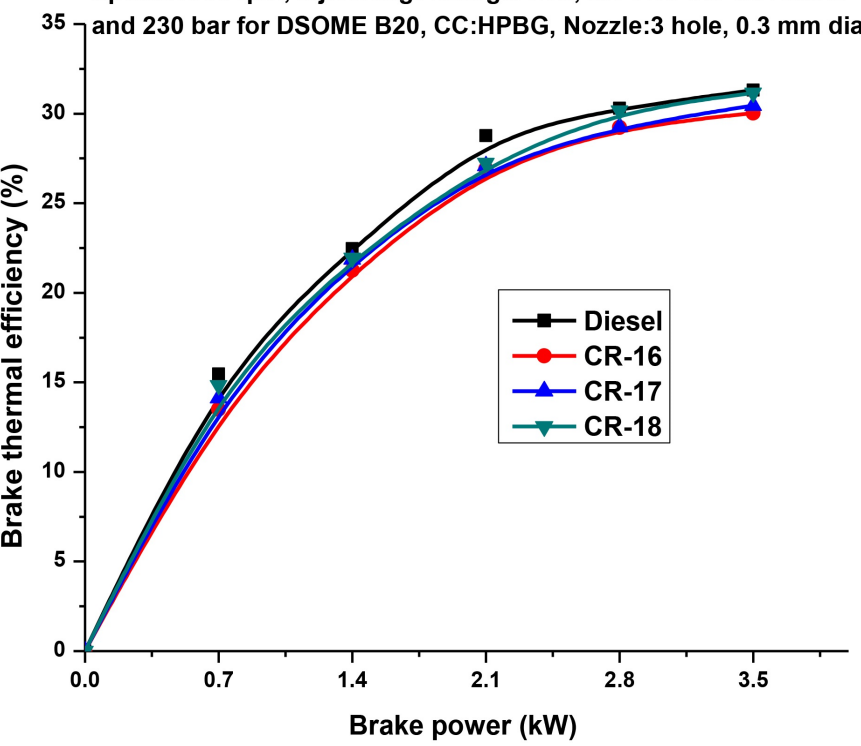

Fig.9. Brake thermal efficiency vs. brake power for neat diesel and DSOME-B20 at different compression ratios (CR).

nozzle orifice diameter of $0.210 \mathrm{~mm}$ compared with 3-hole $(0.280 \mathrm{~mm})$ and 5 hole $(0.240 \mathrm{~mm})$ nozzles. This in turn led to smaller fuel droplets sizes resulting in less relative velocity and hence, partial suffocation with combustion products (Belagur and Chitimini, 2010; Venkanna and Reddy, 2011). Overall and based on the results obtained, the 5-hole nozzle injector, IOP of 230, IT of 26.deg.bTDC, and CR of 18 were considered as optimal operating conditions when running on DSOME-B20. These conditions were used to examine the effect of piston bowl geometry on diesel engine performance and emission characteristics.

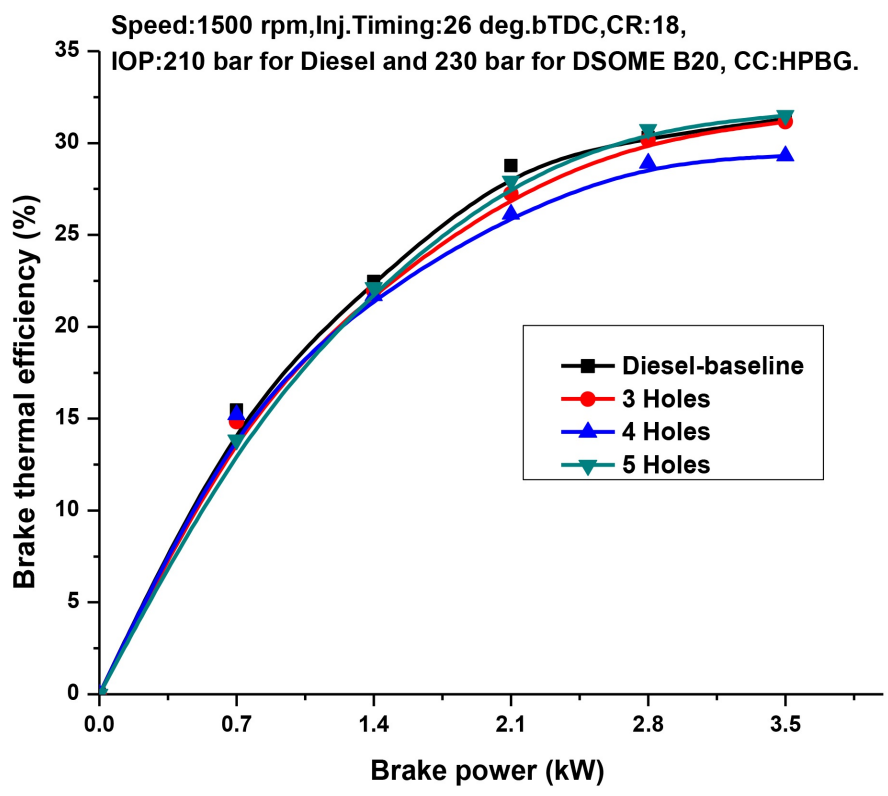

Fig.10. Brake thermal efficiency $v s$. brake power for neat diesel and DSOME-B20 using nozzles with different hole number.
3.2. Effect of piston bowl geometry on diesel engine performance and emission characteristics

\subsubsection{Brake thermal efficiency}

Figure 11 shows the changes in BTE against BP in response to different engine geometries under the optimized operating conditions determined previously. In the SE operation, it was observed that BTE of DSOME-B20 was lower than that of mineral diesel at all loads. This could be due to the lower calorific value, higher density, and greater viscosity of the biodiesel blend. Whereas using the modified engine (ME) running on DSOME-B20, BTE was improved in comparison with the SE (Fig. 11) which could be ascribed to improved fuel atomization, increased cylinder temperature, and more time availability for fuel-air mixing; collectively leading to a more efficient combustion process. The BTE results for Diesel-SE, DSOMEB20-SE, HPBG-ME, and TPBG-ME at full load were found to be $31.32 \%$, $29.93 \%, 31.50 \%$ and $31.69 \%$, respectively. TPBG-ME showed greater BTE values for the entire load range compared with the HPBG-ME which could be attributed to the enhanced air motion and heat transfer in the TPBG leading to proper mixing of burned and unburned fluid particles along with better air-fuel mixture formation and evaporation and consequently more complete combustion (Payri et al., 2004; Prasad et al., 2011; Jaichandar and Annamalai, 2012). On the contrary, insufficient turbulence (air swirl) in the combustion chamber when the HPBG-ME was used led to a poor burning efficiency and consequently lower BTE values (Fig. 11).

Speed:1500 rpm, Inj.Timing (IT):26 Deg.bTDC, IOP:210 bar for Diesel

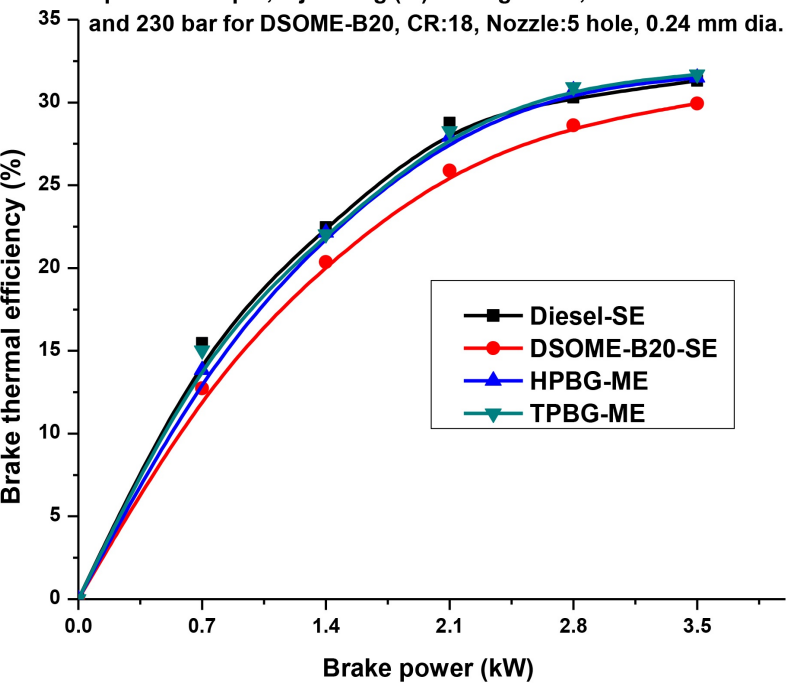

Fig.11. Brake thermal efficiency vs. brake power for different engine geometry. Diesel-SE Diesel-operated standard engine; DSOME-B20-SE: $20 \%$ biodiesel-operated standard engine; HPBG-ME: Modified engine with HPBG piston geometry; and TPBG-ME: Modified engine with TPBG piston geometry.

\subsubsection{Brake specific fuel consumption}

Figure 12 represents the trends of BSFC against BP for SE and ME engine operated on DSOME-B20 fuel blend. More specifically, higher BSFC values were recorded for SE running on DSOME-B20 in comparison with mineral diesel. This could be justified by the lower heating vale and higher density of DSOME-B20. While engine operation with HPBG-ME running on biodiesel was associated with lower BSFC values when compared to DSOME-B20-SE. In fact, in the modified engine with the HPBG geometry, little amount of fuel would be introduced into the cylinder when the piston was at the top dead centre (TDC) leading to rapid HRR. Comparing the two geometries investigated and as presented in Figure 12, it could be observed that TPBG-ME had lower BSFC values vs. HPBG-ME which could be attributed to the enhanced air-fuel mixing caused by the powerful squish and swirl motions inside the combustion chamber. The BSFC results at full load for Diesel-SE, DSOME-B20-SE, HPBG-ME, and TPBG-ME were $0.290 \mathrm{~kg} / \mathrm{kW} . \mathrm{h}, 0.320 \mathrm{~kg} / \mathrm{kW} . \mathrm{h}, 0.297 \mathrm{~kg} / \mathrm{kW} . \mathrm{h}$ and 0.292 $\mathrm{kg} / \mathrm{kW} . \mathrm{h}$, respectively. 


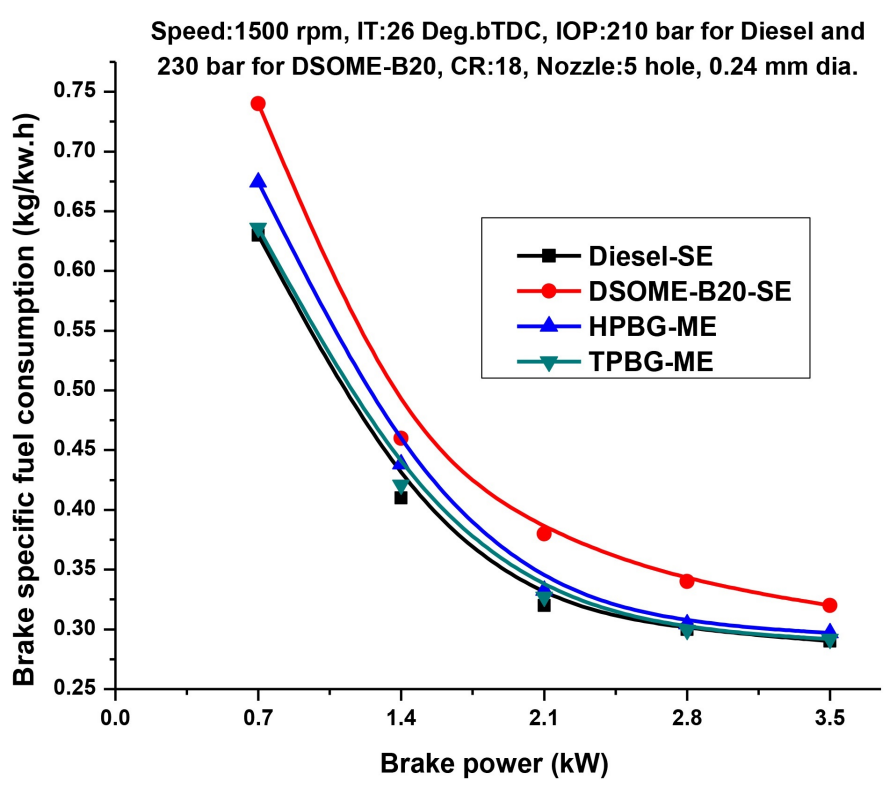

Fig.12. Brake specific fuel consumption vs. brake power for different engine geometry. DieselSE: Diesel-operated standard engine; DSOME-B20-SE: 20\% biodiesel-operated standard engine; HPBG-ME: Modified engine with HPBG piston geometry; and TPBG-ME: Modified engine with TPBG piston geometry.

\subsubsection{HC emission}

Figure 13 depicts $\mathrm{HC}$ emissions against $\mathrm{BP}$ for standard and modified engines. In SE operation, $\mathrm{HC}$ emissions are mainly caused by wall quenching, lubricating oil burning, and lean mixture. Using SE configuration, HC emissions when running on DSOME were lower compared with mineral diesel. This might be due to increased gas temperature in the cylinder and higher presence of oxygen when DSOME-B20 was used. Engine modifications in general led to decreased $\mathrm{HC}$ emissions which might be attributed to more efficient fuel atomization, faster evaporation rate, and increased cylinder temperature. Comparing the two geometries investigated using DSOM-B20, the TPBG-ME was revealed to result in lower HC emissions vs. the HPBGME. The reason behind such differences could be the generation of more turbulent kinetic energy (TKE) inside the combustion chamber with improved air-fuel mixing leading to more efficient oxidation and combustion processes of the fuel introduced into the combustion chamber. The $\mathrm{HC}$ emissions values recorded at full load for Diesel-SE, DSOME-B20-SE, HPBG-ME and TPBGME stood at found to be 45, 40, 37, and 34 ppm, respectively (Fig. 13)

\subsection{4. $\mathrm{CO}$ emission}

The differences between standard and modified engines in terms of $\mathrm{CO}$ emissions against BP are shown in Figure 14. It is well known that the CO emissions of biodiesel and its blends are in general lower than that of the mineral diesel due to the oxygen content of biodiesel leading to a complete combustion. The MEs running on DSOME-B20 resulted in lower CO emissions than the SE. This is ascribed to the greater cylinder temperatures in the MEs leading to faster evaporation of the fuel droplets and consequently faster oxidation to $\mathrm{CO}$ into $\mathrm{CO}_{2}$. The $\mathrm{SE}$ operation with neat diesel was associated with the highest $\mathrm{CO}$ emission of $0.089 \%$ when compare to biodiesel operations in both SE and ME configurations. This could be attributed to the lower oxygen presence in the diesel fuel when compare to DSOME-B20.

The TPMBG-ME showed the lowest $\mathrm{CO}$ emission of $0.065 \%$ in comparison with the other engine geometry, i.e., HPBG-ME $(0.068 \%)$. This difference could be explained by the improved air motion in the cylinder, releasing more heat, and hence, increased combustion temperature which in turn enhanced the oxidation and combustion processes.

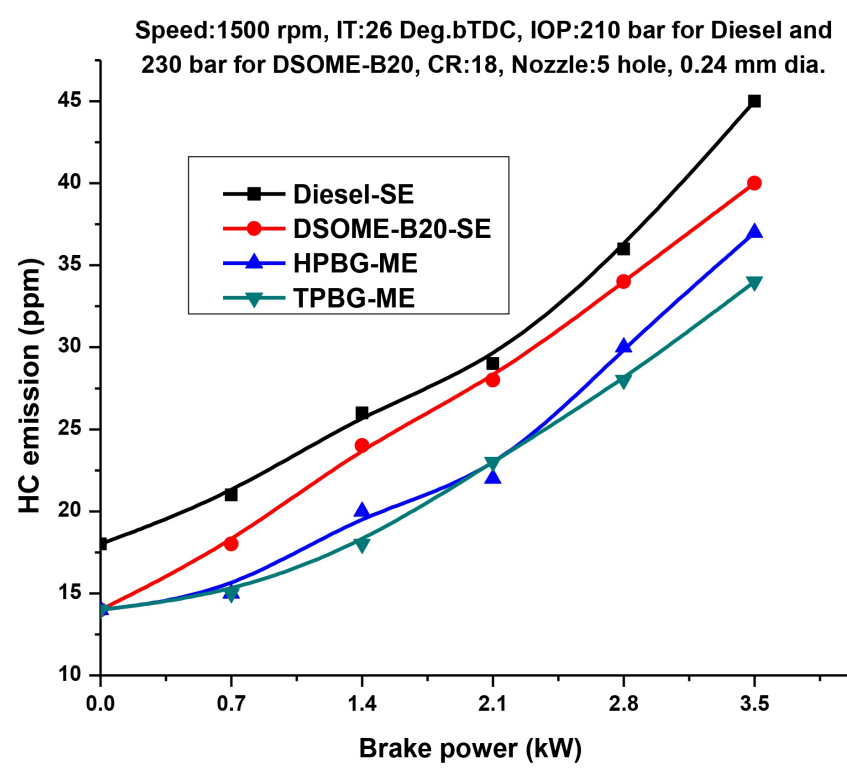

Fig.13. HC emissions $v s$. brake power for different engine geometry. Diesel-SE: Dieseloperated standard engine; DSOME-B20-SE: $20 \%$ biodiesel-operated standard engine; HPBG-ME: Modified engine with HPBG piston geometry; and TPBG-ME: Modified engine with TPBG piston geometry.

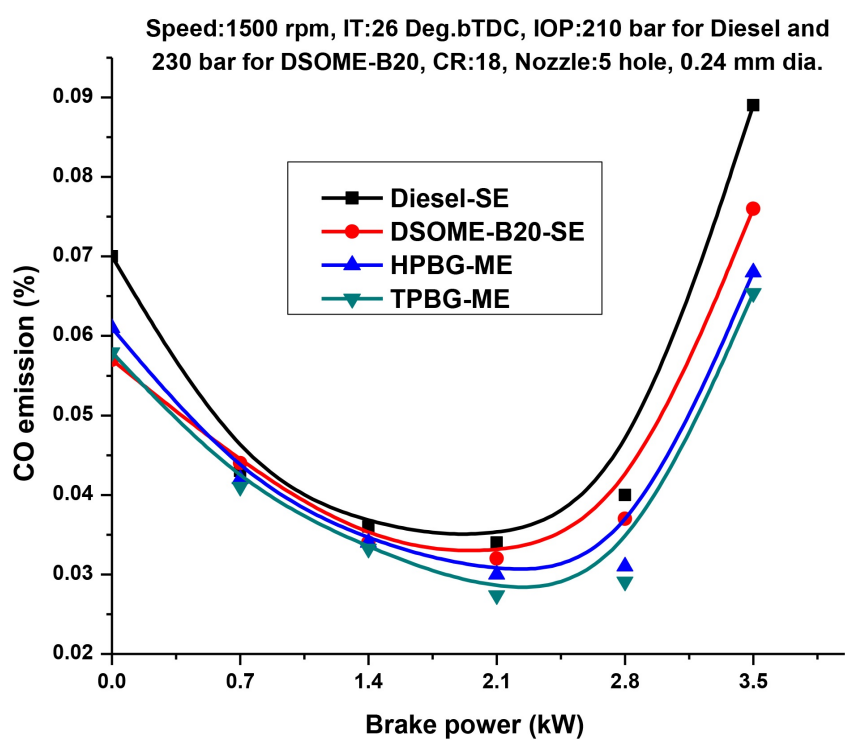

Fig.14. CO emission $v s$. brake power for different engine geometry. Diesel-SE: Dieseloperated standard engine; DSOME-B20-SE: $20 \%$ biodiesel-operated standard engine; HPBG-ME: Modified engine with HPBG piston geometry; and TPBG-ME: Modified engine with TPBG piston geometry.

\subsubsection{Nitrogen oxides emission}

Figure 15 depicts the variations in NOx emissions at different loads for standard and modified engines running on DSOME-B20. High cylinder temperatures and the presence of oxygen are the reason behind NOx formation in diesel engines. As shown in Figure 15, as load increased NOx emissions were also increased. NOx emission was found to be greater for DSOME-B20 fuel when compared to mineral diesel at all loads. Higher 
HRR during premixed combustion phase observed with biodiesel fuels led greater cylinder temperature and improved combustion. The NOx emission results at full load for Diesel-SE, DSOME-B20-SE, HPBG-ME, and TPBGME were 961, 978, 1118, and $1065 \mathrm{ppm}$, respectively. The higher NOx emissions observed in response to engine modifications could be attributed to the improved turbulent motion of air leading to intensified heat release and heat transfer and consequently increased combustion temperature and NOx formation. It should be noted that these NOx emissions could be controlled with the implementation of exhaust gas recirculation (EGR).

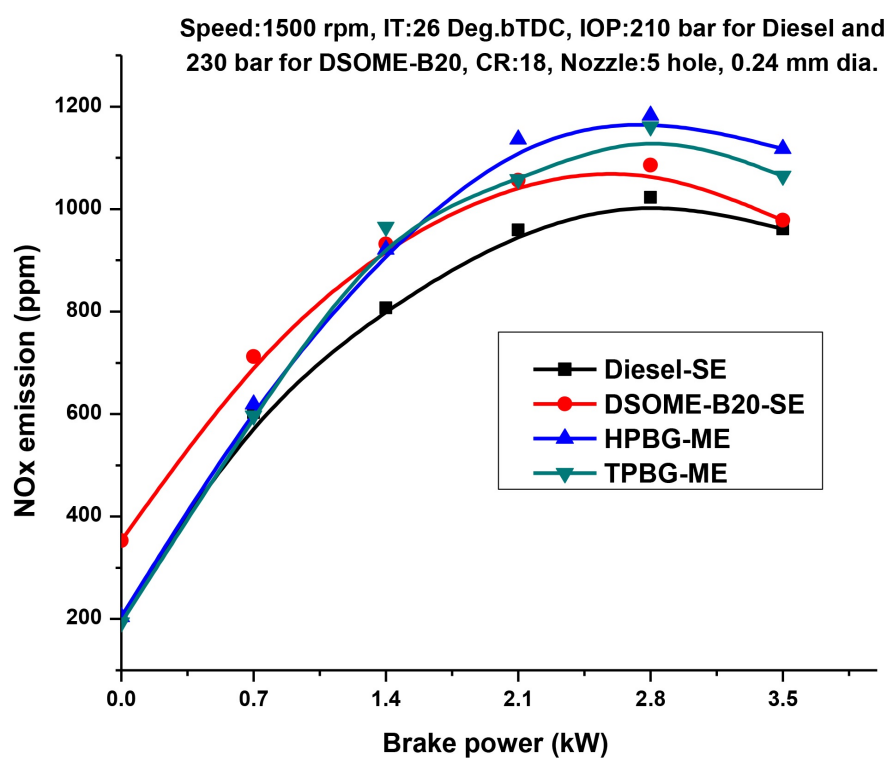

Fig.15. NOx emission $v s$. brake power for different engine geometry. Diesel-SE: Diesel-operated standard engine; DSOME-B20-SE: $20 \%$ biodiesel-operated standard engine; HPBG-ME: Modified engine with HPBG piston geometry; and TPBG-ME: Modified engine with TPBG piston geometry.

\subsubsection{Cylinder pressure}

The variations in cylinder pressure $v s$. crank angle at full load various engine configurations are presented in Figure 16. As shown the peak cylinder pressure was increased as load increased. In SE operation, neat diesel led to higher peak pressure compared with DSOME-B20. This could be explained by the higher calorific value and lower viscosity of neat diesel than DSOME-B20. When running on biodiesel, the TPBG-ME resulted in the highest cylinder pressure followed by HPBG-ME and DSOME-B20-SE. The higher cylinder pressure recorded for TPBG-ME could be attributed to more turbulence resulting in higher flame speed and consequently rapid combustion of fuel droplets in the combustion chamber. The rapid combustion process in turn led to increased pressure waves when the piston was at TDC hence, resulting in the highest cylinder pressure when compared to non-turbulent HPBG-ME. The cylinder pressure values at full load for Diesel-SE, DSOME-B20-SE, HPBG-ME, and TPBG-ME were found to be 53.63, 52.29, 53.25, and 53.34 bar, respectively.

\subsubsection{Heat release rate}

HRR profiles $v s$. crank angle for standard and modified engines at full load are presented in Figure 17. Apparently, the higher heating value and lower viscosity of neat diesel resulted in higher HRR than DSOME-B20-SE when SE configuration was used. Engine modifications in general increased HRR. More specifically, the maximum HRR was associated with HPBG-ME. This might be attributed to the improved air-fuel mixing rate as well as faster evaporation and combustion under optimized operating parameters of the engine fueled with DSOME-B20 at the diffusion combustion phase. The HRR results at full load for Diesel-SE, DESOME-B20-SE, HPBG-ME, and TPBG-ME were $65.43,57.14,64.72,69.05 \mathrm{~J} /$ crank angle, respectively.
As shown in Figure 17, the TPBG-ME was revealed to lead to higher HRR in comparison with HPBG-ME. The reason behind this difference could be the higher turbulence, more efficient mixing of fuel and air during compression, and the resultant enhanced chemical reaction at the uncontrolled combustion phase. These led to a more complete burning of weak charges hence, increased heat releases and heat transfer to the cylinder wall. Whereas in the case of open type combustion chamber, i.e., HPBGME, HRR was less as the higher surface-volume ratio led to lower pressures and HRRs at different locations of the piston cavity causing lower flame speeds.

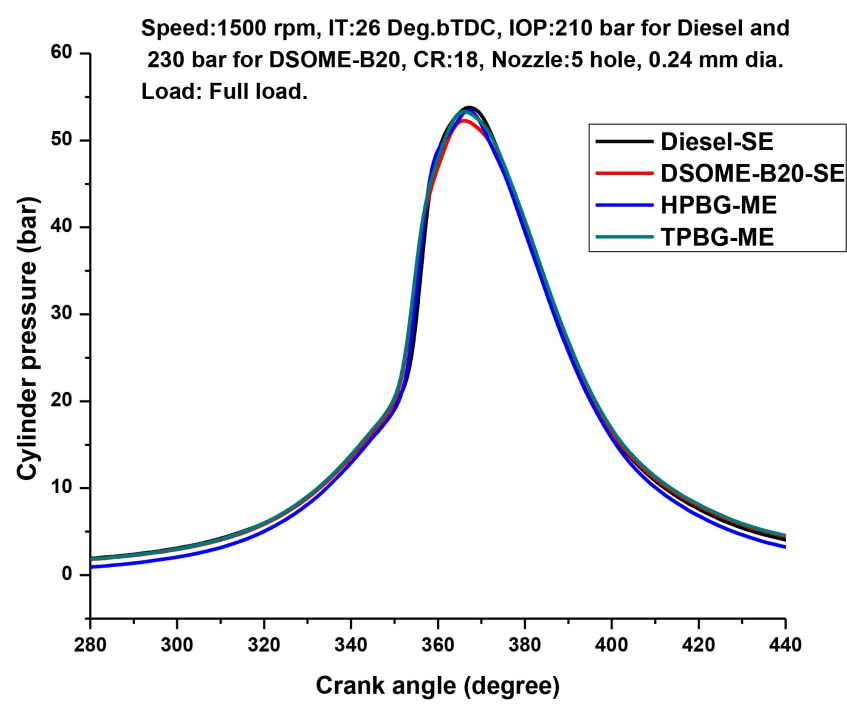

Fig.16. Cylinder pressure vs. crank angle at full load for different engine geometry. Diesel SE: Diesel-operated standard engine; DSOME-B20-SE: $20 \%$ biodiesel-operated standard engine; HPBG-ME: Modified engine with HPBG piston geometry; and TPBG-ME: Modified engine with TPBG piston geometry.

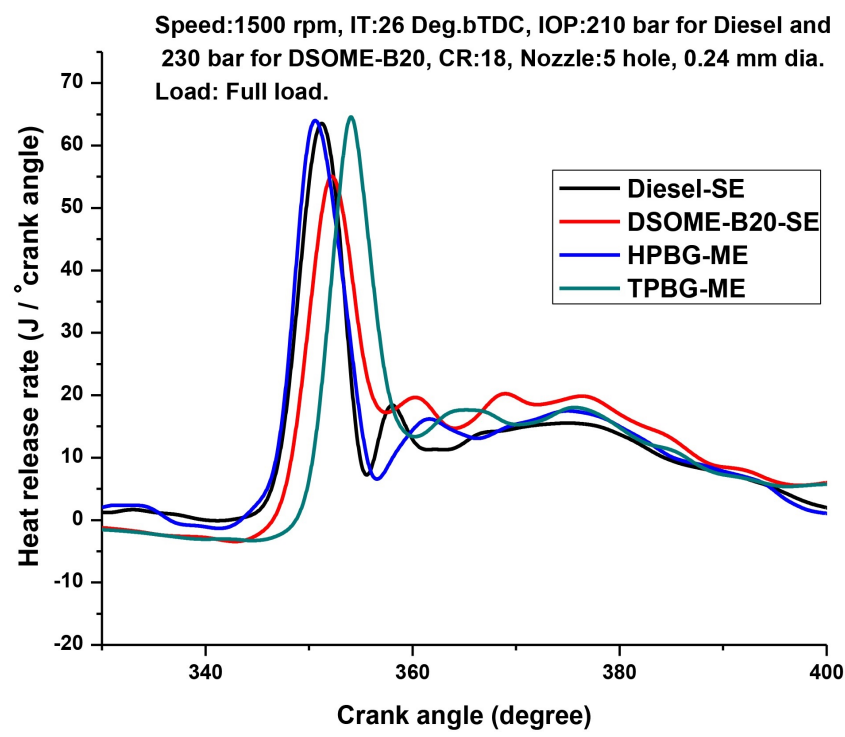

Fig.17. Heat release rate $v s$. crank angle at full load for different engine geometry. DieselSE: Diesel-operated standard engine; DSOME-B20-SE: $20 \%$ biodiesel-operated standard engine; HPBG-ME: Modified engine with HPBG piston geometry; and TPBG-ME: Modified engine with TPBG piston geometry. 


\section{Conclusions}

The present study explored the influence of piston bowl geometry on diesel engine combustion characteristic under optimized operating conditions for $20 \%$ blend of dairy scum oil biodiesel (B20) (i.e., IOP: 230 bar, IT: 26.deg.bTDC, CR: 18, and NH: 5 holes) and the experimental results obtained were compared with the standard diesel engine operating conditions (i.e., IOP: 210 bar, IT: 26.deg.bTDC, CR: 17.5, and NH:3 holes). The following conclusions could be drawn:

1) The TPBG-ME showed an increased BTE of $5.55 \%$ and reduced BSFC of $8.75 \%$ when compared to DSOME-B20-SE.

2) The TPBG-ME resulted in lower emissions, i.e., $\mathrm{HC}$ by $15 \%$ and $\mathrm{CO}$ by $14.47 \%$ when compared to the DSOME-B20-SE. However, the TPBG-ME led to a $8.16 \%$ increase in NOx emission vs. DSOME-B20-SE.

3) HRR was increased by $17.24 \%$ using the TPBG-ME in comparison with the DSOME-B20-SE

Overall, the experimental results obtained confirmed that the toroidal geometry of the piston bowl, i.e., TPBG-ME, was associated with improved combustion characteristics when compared with the hemispherical geometry and the standard engine (DSOME-B20-SE). These improvements could be attributed to the smaller-sized fuel droplets, improved fuel atomization, increased cylinder temperature, higher flame front velocity of the charge, enhanced swirl-squish, and TKE during combustion. Such findings could assist with the fabrication of diesel engines which are more efficiently compatible with biodiesel and its blends.

\section{References}

[1] Agarwal, A.K., Som, S., Shukla, P.C., Goyal, H., Longman, D., 2015. In-nozzle flow and spray characteristics for mineral diesel, Karanja, and Jatropha biodiesels. Appl. Energy. 156, 138-148.

[2] Agarwal, D., Kumar, L., Agarwal, A.K., 2008. Performance evaluation of a vegetable oil fuelled compression ignition engine. Renew. Energy. $33(6), 1147-1156$

[3] Badami, M., Nuccio, P., Trucco, G., 1999. Influence of injection pressure on the performance of a DI diesel engine with a common rail fuel injection system. SAE Technical Paper (1999-01-0193).

[4] Behera, P., Murugan, S., 2013. Studies on a diesel engine fuelled with used transformer oil at different fuel injection nozzle opening pressures. Int. J. Ambient Energy. 34(1), 53-59.

[5] Belagur, K.V., Chitimini, R.V., 2010. Effect of injector opening pressures on the performance, emission and combustion characteristics of DI diesel engine running on honne oil and diesel fuel blend. Therm. Sci. 14(4), 1051-1061.

[6] De Risi, A., Donateo, T., Laforgia, D., 2003. Optimisation of the combustion chamber of direct injection diesel engines. SAE Technical Paper (2003-01-1064)

[7] Geng, P., Mao, H., Zhang, Y., Wei, L., You, K., Ju, J., Chen, T., 2017. Combustion characteristics and NOx emissions of a waste cooking oil biodiesel blend in a marine auxiliary diesel engine. Appl. Therm. Eng. $115,947-954$.

[8] Ghodke, P.R., Suryawanshi, J.G., 2015. Investigation of diesel engine for low exhaustEmissions with different combustion chambers. Therm. Sci. 19(6), 2013-2024

[9] He, Z., Zhong, W., Wang, Q., Jiang, Z., Shao, Z., 2013. Effect of nozzle geometrical and dynamic factors on cavitating and turbulent flow in a diesel multi-hole injector nozzle. Int. J. Therm. Sci. 70, 132-143.

[10] Hountalas, D.T., Kouremenos, D.A., Binder, K.B., Schwarz, V., Mavropoulos, G.C., 2003. Effect of injection pressure on the performance and exhaust emissions of a heavy duty DI diesel engine. SAE Technical Paper (2003-01-0340).

[11] Hwang, J., Qi, D., Jung, Y., Bae, C., 2014. Effect of injection parameters on the combustion and emission characteristics in a common-rail direct injection diesel engine fueled with waste cooking oil biodiesel. Renew. Energy. 63, 9-17.

[12] Jafari, B., Ganji, D.D., 2013. Numerical investigation in the effect of number of nozzle hole on performance and emission in dual fuel engine. Int. J. Automot. Eng. 3(2), 412-423
[13] Jaichandar, S., Annamalai, K., 2012. Effects of open combustion chamber geometries on the performance of pongamia biodiesel in a DI diesel engine. Fuel. 98, 272-279

[14] Jose, D.M., Prasad, B.D., Raj, R.E., Kennedy, Z.R., 2014. An extraction and performance analysis of rubber seed-methyl ester on an IC engine at various compression ratios. Int. J. Green Energy. 11(8), 808-821

[15] Kumar, M.V., Babu, A.V., Kumar, P.R., 2018. Experimental investigation on the effects of diesel and mahua biodiesel blended fuel in direct injection diesel engine modified by nozzle orifice diameters. Renew. Energy. 119, 388-399.

[16] Lahane, S., Subramanian, K.A., 2014. Impact of nozzle holes configuration on fuel spray, wall impingement and NOx emission of a diesel engine for biodieselediesel blend (B20). Appl. Therm. Eng. 64 (1-2), 307-314

[17] Mani, M., Nagarajan, G., 2009. Influence of injection timing on performance, emission and combustion characteristics of a DI diesel engine running on waste plastic oil. Energy. 34(10), 1617-1623

[18] Mamilla, V.R., Mallikarjun, M.V., Rao, G.L.N., 2013. Effect of combustion chamber design on a di diesel engine fuelled with jatropha methyl esters blends with diesel. Procedia Eng. 64, 479-490.

[19] Miraculas, G.A., Bose, N., Raj, R.E., 2016. Optimization of biofue blends and compression ratio of a diesel engine fueled with Calophyllum inophyllum oil methyl ester. Arabian J. Sci. Eng. 41(5), 1723-1733.

[20] Mohanraj, T., Mohan Kumar, K.M., 2013. Operating characteristics of a variable compression ratio engine using esterified Tamanu oil. Int. J. Green Energy. 10(3), 285-301

[21] Payri, F., Benajes, J., Margot, X., Gil, A., 2004. CFD modeling of the in-cylinder flow in direct-injection diesel engines. Comput. Fluids. 33(8), 995-1021

[22] Prasad, B.V.V.S.U., Sharma, C.S., Anand, T.N.C., Ravikrishna, R.V., 2011. High swirl-inducing piston bowls in small diesel engines for emission reduction. Appl. Energy. 88(7), 2355-2367.

[23] Ramadhas, A.S., Jayaraj, S., Muraleedharan, C., 2004. Use ofvegetable oils as I.C. engine fuels-a review. Renew. Energy. 29(5), 727-742

[24] Reddy, M.S., Sharma, N., Agarwal, A.K., 2016. Effect of straigh vegetable oil blends and biodiesel blends on wear of mechanical fuel injection equipment of a constant speed diesel engine. Renew. Energy. 99, 1008-1018.

[25] Selaimia, R., Beghiel, A., Oumeddour, R., 2015. The synthesis of biodiesel from vegetable oil. Procedia Social Behav. Sci. 195, 16331638.

[26] Senthil, R., Silambarasan, R., Ravichandiran, N., 2015. Influence of injection timing and compression ratio on performance, emission and combustion characteristics of Annona methyl ester operated diesel engine. Alexandria Eng. J. 54(3), 295-302.

[27] Song, J., Yao, C., Liu, Y., Jiang, Z., 2008. Investigation on flow field in simplified piston bowls for DI diesel engine. Eng. Appl. Comput. Fluid Mech. 2(3), 354-365.

[28] Vairamuthu, G., Sundarapandian, S., Thangagiri, B., 2016. Use o calophyllum inophyllum biofuel blended with diesel in DI diesel engine modified with nozzle holes and its size. Heat Mass Transfer. 52(5), 1005-1013.

[29] Venkanna, B.K., Reddy, C.V., 2011. Influence of injector opening pressures on the performance, emission and combustion characteristics of DI diesel engine running on calophyllum inophyllum linn oil (honne oil). Int. J. Renew. Energy. 6(1), 15-24.

[30] Yadav, A.K., Khan, M.E., Pal, A., 2017. Kaner biodiesel production through hybrid reactor and its performance testing on a CI engine at different compression ratios. Egypt. J. Pet. 26(2), 525-532. 